\title{
Prenatal Sonographic Detection of Birth Defects in 18 Hospitals From South America
}

\author{
Hebe Campaña, PhD, Mónica Ermini, MD, Horacio A. Aiello, MD, \\ Hugo Krupitzki, MD, Eduardo E. Castilla, Jorge S. López-Camelo, PhD, \\ Latin American Collaborative Study of Congenital Malformations \\ Study Group
}

\begin{abstract}
Abbreviations
$\mathrm{Cl}$, confidence interval; ECLAMC, Latin American Collaborative Study of Congenital Malformations
\end{abstract}

Received June 16, 2009, from the Instituto Multidisciplinario de Biología Celular, La Plata, Argentina (H.C., J.S.L.-C.); Servicio de Obstetricia del Hospital Italiano de La Plata, La Plata, Argentina (M.E.); Servicio de Obstetricia del Hospital Italiano de Buenos Aires, Buenos Aires, Argentina (H.A.A.); Dirección de Investigación, Center for Medical Education and Clinical Research, Buenos Aires, Argentina (H.K., E.E.C., J.S.L.-C.); and Latin-American Collaborative Study of Congenital Malformations, Instituto Oswaldo Cruz, Rio de Janeiro, Brazil (E.E.C.). Revision requested July 7, 2009. Revised manuscript accepted for publication September 21, 2009.

We thank the sonographers for their willing participation in this project and Alfredo Uranga, MD, Viviana Cosentino, PhD, and Mónica Rittler, PhD, for helpful advice during the investigation. Members of the Study Group are listed after "Discussion." This work was supported in part by grant 6177 from the National Council for Scientific Research and the Scientific Research Commission of Buenos Aires and grants 40.3444/2004-7 and 40.1467/2004-0 from Conselho Nacional de Desenvolvimento Científico e Tecnológico of Brazil.

Address correspondence to Jorge S. LópezCamelo, PhD, Laboratory of Genetic Epidemiology, Instituto Multidisciplinario de Biología Celular, CC 403-1900 La Plata, Argentina.

E-mail: jslc@eclamc.org.ar

Article includes CME test
Objective. The purpose of this study was to assess the accuracy of prenatal sonographic diagnosis of birth defects and the gestational age at detection according to the health insurance schemes of mothers in $\mathbf{4 5 0}$ malformed neonates from 18 South American hospitals on the basis of prenatal sonographic records. Methods. Between July 2000 and December 2003, 18 hospitals included in the Latin American Collaborative Study of Congenital Malformations (13 from Argentina [8 public and 5 nonpublic], 3 from Brazil [2 public and 1 nonpublic], 1 from Chile [nonpublic], and 1 from Venezuela [public]) voluntarily participated in this prospective observational study, recording fetuses with sonographically detected malformations. Prenatal sonographic descriptions of anomalies were compared with those recorded at birth. Results. Of 812 anomalies detected at birth, 457 had been prenatally detected (detection rate, 56.3\%; 95\% confidence interval, 52.8\%-59.8\%). Before 24 gestational weeks, anencephaly had the highest detection rate. Cleft lip and clubfoot were more easily detected when associated with other anomalies. The detection rates for central nervous system and renourinary malformations were greater than $80 \%$. Detection rates between both health insurance schemes (public and nonpublic) did not show significant differences, but anencephaly, spina bifida, renourinary defects, and cleft lip with or without cleft palate were detected earlier in patients from nonpublic rather than in public hospitals. Conclusions. For specific anomalies, South America shows similar levels of prenatal sonographic detection as developed countries. Detection rates during pregnancy were similar for public and nonpublic hospitals, whereas cases were diagnosed earlier in patients from nonpublic hospitals. Key words: birth defects; health insurance scheme; Latin American Collaborative Study of Congenital Malformations; prenatal sonography; South America.

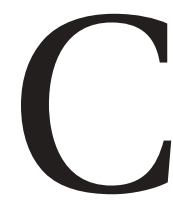

urrently, more than half of malformed neonates can have their conditions prenatally diagnosed by sonography. A number of European multicenter programs focusing on prenatal diagnosis, such as Eurofetus, Euroscan, and Eurocat, have found a sonographic congenital malformation detection rate of $60 \% .^{1-5}$ This rate varies widely among countries according to the availability of sonography and the use of prenatal screening as well as the individual parental decision to continue a pregnancy. ${ }^{6}$ 
Several studies evaluating population- and hospital-based sonographic performance have shown a wide range of accuracy rates, depending on the strategy used for screening, different local policies related to prenatal screening, sonographer and sonologist training, and the risk level of the population examined..$^{7-13}$

To our knowledge, prenatal sonographic detection of birth defects has not been assessed for South American populations to date, and although sonography has become a standard practice in prenatal care, no information exists in South America combining prenatal sonographic findings and postnatal diagnoses of birth defects.

Access to prenatal care services in South America differs among pregnant women according to their place of residence, socioeconomic status, and the health insurance scheme available. This population shows substantial differences because patients at high socioeconomic levels follow the patterns of developed countries, whereas those of lower socioeconomic levels are deprived of adequate prenatal care. ${ }^{14}$

The first group attends nonpublic hospitals, for which private insurance is required. Thus, they have access to genetic counseling, prenatal screening, and prenatal diagnosis. ${ }^{15,16}$ Patients from lower socioeconomic groups attend public hospitals, most of them free or with very low costs. These mothers are younger, with lower education levels and lower numbers of prenatal visits. ${ }^{14}$ Sonography in public hospitals is mainly performed for specific clinical indications. Although there is an increasing trend for fetal anomaly scanning in high-risk groups of pregnant women, better technology, and higher accessibility to professional training, populations with low socioeconomic resources still show limited access to prenatal care and consequently late diagnoses. ${ }^{14,17}$ Therefore, differences in sonographic diagnoses of birth defects may be expected, although this assumption has not yet been explored..$^{18,19}$

The aims of this study were to assess prenatal detection of congenital malformations by fetal sonography in a birth series from 18 South American maternity hospitals and to analyze differences in diagnostic accuracy according to the types of malformations, gestational ages at diagnosis, and health insurance schemes of the mothers (nonpublic and public).

\section{Materials and Methods}

\section{Data Collection}

The Latin American Collaborative Study of Congenital Malformations (ECLAMC) is a research program for the clinical and epidemiologic investigation of risk factors in the etiology of birth defects. Its network comprises 80 maternity hospitals distributed among 10 South American countries, where neonates with birth defects are ascertained, their conditions diagnosed, and their information registered. ${ }^{20}$

Between July 2000 and December 2003, 18 ECLAMC hospitals (13 from Argentina [8 public and 5 nonpublic], 3 from Brazil [2 public and 1 nonpublic], 1 from Chile [nonpublic], and 1 from Venezuela [public]) voluntarily participated in this prospective observational study, recording fetuses with sonographic detection of malformations. Because there are different recommendations and guidelines for fetal sonographic examination across South American countries, a specific form was designed for this study. This form included descriptive information about the case, the gestational age according to the last menstrual period or first-trimester sonography, fetal measurements (biparietal diameter, femur length, and abdominal circumference). These guidelines also included a list of organs and systems to be examined, which were organized into 14 major groups (skull, intracranial structures, face and neck, spine, cardiovascular system, rest of the thorax, diaphragm, abdominal wall, digestive system, urogenital system, limbs, intrauterine growth restriction, ovular adnexa [placenta, cord, membrane, and amniotic fluid] and other), and a description of the detected anomaly and suspected diagnosis ("Appendix"). Sonographic examinations were performed by trained staff sonographers using high-resolution equipment.

All sonographic records with diagnosed anomalies were sent to the coordinating group. Trained pediatricians ascertained neonates at birth, diagnosed their conditions, and sent their medical records to the coordinating group, where prenatal and at-birth records were linked by an identification code. Sonographic detection rates were compared with at-birth outcomes for each malformation. 
The anomalies detailed below were selected for analysis: abdominal wall defects (omphalocele, gastroschisis, and other defects); anencephaly (anencephaly and acrania); spina bifida (with or without hydrocephaly); hydrocephaly (without spina bifida); other specified anomalies of the brain (cephalocele, microcephaly, and others); heart and great vessel anomalies; cleft lip with or without cleft palate; renourinary system malformations (renal agenesis, cystic kidney disease, congenital obstructive defects of the urinary tree, and other malformations of the kidneys and urinary system); clubfoot (talipes equinovarus, talovalgus, and cavum); limb reduction anomalies; and skeletal malformations (birth defects of the skull, spine, ribs, and sternum, skeletal dysplasias, and other specified anomalies of bones and cartilage). Minor congenital malformations were excluded from the study. Anomalies detected in fewer than 12 cases were grouped as "other."

The following data were obtained from the sonographic record for each case: gestational age by last menstrual period at diagnosis; affected organs, systems, or adnexa (amniotic fluid, cord, and placenta); description of the anomalies; and suspected diagnoses.

The health insurance schemes of the hospitals of birth were classified as public when care was provided free of charge (state hospitals) and nonpublic when patients were charged a premium cost directly or indirectly through a health insurance scheme.

\section{Data Analysis}

Prenatal sonographic descriptions of anomalies were compared with those recorded at birth. When prenatal and postnatal diagnoses coincided, they were classified as true-positive; when the malformation prenatally observed differed from the one detected during the neonatal examination, it was classified as a misdiagnosis; and for multimalformed cases, anomalies detected at birth that were prenatally undetected were classified as not detected.

Detection rates were estimated as true-positive anomalies over total anomalies confirmed at birth. Misdiagnosis rates were defined as the numbers of incorrectly diagnosed anomalies over the total numbers of prenatally diagnosed anomalies. Scanning specificity could not be estimated because nonmalformed neonates were not included in this study.

Defect detection rates were analyzed according to gestational ages (before or after 24 gestational weeks), presence or absence of associated malformations, and health insurance schemes of the mothers. Values were expressed as observed to expected ratios and 95\% confidence intervals (CIs) following Poisson distribution. Differences were evaluated by $t$ and Mann-Whitney tests for continuous variables normally and non-normally distributed, respectively. The significance level $P<.05$ was used.

Anomalous fetuses (total cases) as well as anomalies (total diagnoses) were counted for data analysis. Thus, a fetus presenting 2 anomalies was considered as 1 anomalous fetus but as 2 birth defects.

This study followed the principles set out in the Declaration of Helsinki and its amendments, and the International Guidelines for Biomedical Research on Epidemiological Studies from the Council of International Organizations of Medical Sciences. Identifying data of women included in this study were anonymously collected, and all steps in the study were approved by the ECLAMC Ethics Committee at the Center for Medical Education and Clinical Research of Argentina.

\section{Results}

A total of 450 fetuses with prenatally detected malformations were followed until birth. Of these, 316 had a single malformation; 78 had 2; 38 had 3; 12 had 4; 2 had 5; 2 had 6; and 2 had 7. Prenatal sonographic screening detected 670 defects, representing 1.5 defects per fetus.

Prenatally detected anomalies were classified into 11 groups, shown in Table 1 in decreasing order of detection rate. Of all 812 anomalies detected at birth, 457 were prenatally detected as true-positive (56.3\%; 95\% CI, 52.8\%-59.8\%). Detection rates for spina bifida, renourinary system anomalies, anencephaly, abdominal wall defects, and hydrocephaly were greater than $80 \%$, whereas those for cleft lip with or without cleft palate, limb anomalies, and clubfoot were less than $25 \%$. Of 670 prenatally detected anomalies, 213 were misdiagnosed at birth (global misdiagnoses, 31.8\%; 95\% CI, 28.4\%- 
35.6\%). The highest misdiagnosis rates were observed for the following anomalies: cleft lip with or without cleft palate, limb defects, and clubfoot. These defects also showed the lowest detection rates (Table 1).

Of 426 malformed fetuses with specified gestational ages, 101 (23.7\%; 95\% CI, 19.7\%-28.0\%) had diagnoses before 24 gestational weeks (mean gestational age \pm SD, $20.31 \pm 3.19$ weeks). Of 636 prenatally detected anomalies shown in these 426 fetuses with specified gestational ages 157 (24.7\%; 95\% CI, 21.4\%-28.2\%) were detected before 24 weeks.

Of the 426 cases, 101 were diagnosed before 24 gestational weeks (23.7\%; 95\% CI, 19.7\%-28.0\%). Assuming that these frequencies were similar for each anomaly, the number of expected cases was obtained by multiplying the total number of cases for each anomaly by 0.237 . Thus, we could state as an example that $10.2(0.237 \times 43)$ anencephaly cases would be expected to be detected if the rate of detection were $23.7 \%$, and 24 cases were already found. The relationship between the observed to expected ratio $(24 / 10.2=2.35)$ was significant. In this sense, anencephaly was the most frequent malformation detected before 24 weeks (mean gestational age, $20.0 \pm 3.0$ weeks). The chance of early diagnosis was 2.3 times higher for anencephaly than for the remaining anomalies. Conversely, most fetuses with spina bifida had a diagnosis after 24 weeks (mean gestational age, $32.8 \pm 3.3$ weeks; Table 2).

Associated malformations were diagnosed in 134 of 450 fetuses (29.8\%; 95\% CI, $25.6 \%-34.2 \%$ ). Six anomalies showed significantly higher prenatal detection rates than expected when found associated with other defects: clubfoot, cleft lip with or without cleft palate, skeletal malformations, other specified anomalies of the brain, heart and great vessel anomalies, and limb reductions (Table 3).

Of 297 isolated malformations with specified gestational ages, 68 (22.9\%; 95\% CI, 18.2\%-28.1\%) were diagnosed before 24 weeks (mean gestational age, $20.1 \pm 3.5$ weeks); of 129 associated cases, 33 (25.6\%; 95\% CI, 18.3\%-34.0\%) were diagnosed before 24 weeks (mean gestational age, $20.8 \pm 2.5$ weeks). Detection rates showed no significant differences between isolated and associated cases before 24 weeks $\left(\chi_{1 d f}^{2}=0.36 ; P=.549\right)$.

Mothers attending nonpublic hospitals were older with higher maternal education than those from public hospitals. Means for gestational age (weeks) at anomaly detection, gestational age (weeks) at the first prenatal visit, and gestational age (weeks) at the first prenatal scan were lower for patients from nonpublic hospitals than for those from public hospitals. The numbers of sono-

Table 1. Sonographic Detection Rates for 11 Selected Congenital Anomalies

\begin{tabular}{|c|c|c|c|c|c|c|c|}
\hline \multirow[b]{2}{*}{ Anomaly } & \multicolumn{3}{|c|}{ Prenatal } & \multicolumn{2}{|c|}{ At Birth } & \multirow[b]{2}{*}{ DR, \% } & \multirow[b]{2}{*}{ MR, \% } \\
\hline & $\mathbf{N}$ & TP & $\mathrm{MN}$ & $\mathbf{N}$ & ND & & \\
\hline Spina bifida & 71 & 62 & 9 & 66 & 4 & 93.9 & 12.7 \\
\hline Renourinary system & 106 & 78 & 28 & 87 & 9 & 89.7 & 26.4 \\
\hline Anencephaly & 46 & 42 & 4 & 48 & 6 & 87.5 & 8.7 \\
\hline Abdominal wall & 34 & 33 & 1 & 38 & 5 & 86.8 & 2.9 \\
\hline Hydrocephaly & 68 & 63 & 5 & 78 & 15 & 80.8 & 7.4 \\
\hline OSA of brain & 51 & 28 & 23 & 36 & 8 & 77.8 & 45.1 \\
\hline Heart and great vessels & 46 & 38 & 8 & 65 & 27 & 58.5 & 17.4 \\
\hline Skeletal & 33 & 30 & 3 & 57 & 27 & 52.6 & 9.1 \\
\hline CL/P & 19 & 6 & 13 & 26 & 20 & 23.1 & 68.4 \\
\hline Limbs & 29 & 13 & 16 & 67 & 54 & 19.4 & 55.2 \\
\hline Clubfoot & 17 & 9 & 8 & 47 & 38 & 19.1 & 47.1 \\
\hline Subtotal & 520 & 402 & 118 & 615 & 213 & 65.3 & 22.7 \\
\hline Other & 150 & 55 & 95 & 197 & 142 & 27.9 & 63.3 \\
\hline Total & 670 & 457 & 213 & 812 & 355 & 56.3 & 31.8 \\
\hline
\end{tabular}

At birth N indicates TP + ND; CL/P, cleft lip with or without cleft palate; DR, detection rate; Limbs, polydactyly, syndactyly, limb reduction, and other anomalies of the limbs; $M N$, misdiagnosis number; $M R$, misdiagnosis rate; $N$, number of cases with the anomaly; ND, not detected (N); OSA of brain, other specified anomalies of the brain (cephalocele, microcephaly, and others); Other, other diagnoses with less than 12 cases each; Prenatal N, TP + MN; Skeletal, skull, spine, ribs, sternum, skeletal dysplasias, and other specified anomalies of bones and cartilage; and TP, true-positive (N). 
Table 2. Sonographic Detection of Congenital Anomalies by Gestational Age at the Time of Prenatal Diagnosis

\begin{tabular}{|c|c|c|c|c|c|c|c|}
\hline \multirow[b]{2}{*}{ Anomaly } & \multicolumn{4}{|c|}{ Gestational Age, wk $\leq 24$} & \multirow[b]{2}{*}{$P$} & \multicolumn{2}{|c|}{ Total Cases } \\
\hline & $\mathbf{N}$ & DR, \% & Exp & O/E (95\% Cl) & & $\mathbf{N}$ & NS \\
\hline Anencephaly & 24 & 55.8 & 10.2 & $2.35(1.51-3.50)$ & $a$ & 43 & 3 \\
\hline OSA of brain & 16 & 32.0 & 11.9 & $1.34(0.77-2.18)$ & & 50 & 1 \\
\hline Abdominal wall defect & 9 & 37.5 & 7.8 & $1.15(0.53-2.19)$ & & 24 & 1 \\
\hline Clubfoot & 4 & 25.0 & 3.8 & $1.05(0.29-2.70)$ & & 16 & 1 \\
\hline Skeletal & 8 & 25.0 & 7.6 & $1.05(0.45-2.07)$ & & 32 & 1 \\
\hline Renourinary system & 23 & 23.0 & 23.7 & $0.97(0.62-1.46)$ & & 100 & 6 \\
\hline Heart and great vessels & 9 & 20.9 & 10.2 & $0.88(0.40-1.67)$ & & 43 & 3 \\
\hline $\mathrm{CL} / \mathrm{P}$ & 3 & 18.7 & 3.8 & $0.79(0.16-2.31)$ & & 16 & 3 \\
\hline Hydrocephaly & 10 & 15.7 & 15.2 & $0.66(0.32-1.21)$ & & 64 & 4 \\
\hline Limbs & 4 & 13.8 & 6.9 & $0.58(0.16-1.48)$ & & 29 & 1 \\
\hline Spina bifida & 9 & 13.0 & 17.0 & $0.53(0.24-0.99)$ & $\mathrm{b}$ & 69 & 2 \\
\hline Other (<12 cases) & 12 & 25.5 & 11.1 & $1.08(0.56-1.89)$ & & 47 & 3 \\
\hline Total & 101 & 23.7 & & 1.0 & & 426 & 24 \\
\hline
\end{tabular}

Exp indicates number of cases at 24 weeks' gestation or earlier if the detection rate were 0.237 ; NS, not specified; and $\mathrm{O} / \mathrm{E}(95 \% \mathrm{CI})$, observed to expected ratio and $95 \% \mathrm{Cl}$. Other definitions are as in Table 1.

a $P<.01$.

$\mathrm{b} P<.05$.

graphic scans and prenatal visits were significantly higher for nonpublic than for public hospitals. No differences in the numbers of previous pregnancies were observed between groups (public and nonpublic hospitals; Table 4).

Detection rates between both health insurance schemes (public and nonpublic) did not show significant differences, but anencephaly, spina bifida (Figures 1 and 2, respectively), renourinary defects, and cleft lip with or without cleft palate were detected earlier in patients from nonpublic hospitals than those from public hospitals $(P<.05$; Table 5).

\section{Discussion}

Birth defects represent one of the leading causes of infant mortality and disability in South America, showing a steady and progressive rise during the last decades. ${ }^{21-23}$ Early detection of birth defects could reduce their impact on the quality of life of disabled people, allowing the optimization of perinatal clinical management, the use of specialized neonatal and pediatric intensive care, and the timely application of surgical techniques. ${ }^{24-27}$

Table 3. Sonographic Detection Rates for Associated Anomalies in Polymalformed Fetuses

\begin{tabular}{|c|c|c|c|c|c|c|}
\hline \multirow[b]{2}{*}{ Anomaly } & \multicolumn{4}{|c|}{ Associated Cases } & \multirow[b]{2}{*}{$P$} & \multirow{2}{*}{$\frac{\text { Total Cases }}{\mathbf{N}}$} \\
\hline & $\mathbf{N}$ & DR, \% & Exp & O/E (95\% Cl) & & \\
\hline Clubfoot & 17 & 100.0 & 5.1 & $3.33(1.94-5.34)$ & a & 17 \\
\hline CL/P & 17 & 89.5 & 5.7 & $2.89(1.74-4.78)$ & a & 19 \\
\hline Skeletal & 24 & 72.7 & 9.8 & $2.45(1.57-3.64)$ & a & 33 \\
\hline OSA of brain & 36 & 70.6 & 15.2 & $2.36(1.66-3.28)$ & a & 51 \\
\hline Heart and great vessels & 31 & 67.4 & 13.7 & $2.26(1.54-3.21)$ & a & 46 \\
\hline Limbs & 20 & 66.7 & 8.9 & $2.25(1.37-3.47)$ & a & 30 \\
\hline Abdominal wall defect & 16 & 47.0 & 10.1 & $1.58(0.91-2.57)$ & & 34 \\
\hline Hydrocephaly & 24 & 35.3 & 20.3 & $1.18(0.76-1.76)$ & & 68 \\
\hline Renourinary system & 37 & 34.9 & 31.6 & $1.17(0.82-1.61)$ & & 106 \\
\hline Spina bifida & 19 & 26.8 & 21.2 & $0.90(0.54-1.40)$ & & 71 \\
\hline Anencephaly & 7 & 15.2 & 13.7 & $0.51(0.21-1.05)$ & & 46 \\
\hline Other (<12 cases) & 7 & 14.0 & 14.9 & $0.47(0.19-0.97)$ & b & 50 \\
\hline Total & 134 & 29.8 & 134.0 & 1.0 & & 450 \\
\hline
\end{tabular}

Definitions are as in Tables 1 and 2 .

a $P<.01$.

$\mathrm{b} P<.05$ 
Table 4. Selected Characteristics Among Women From Nonpublic and Public Hospitals

\begin{tabular}{|c|c|c|c|c|}
\hline Characteristic & $\begin{array}{c}\text { Nonpublic } \\
(\mathrm{N}=332)\end{array}$ & $\begin{array}{c}\text { Public } \\
(\mathrm{N}=118)\end{array}$ & Test & $P$ \\
\hline Maternal age, $y$, mean \pm SD & $27.9 \pm 6.7$ & $25.6 \pm 6.5$ & $3.30^{\mathrm{a}}$ & .001 \\
\hline Gestational age at detection, wk, mean \pm SD & $28.6 \pm 6.2$ & $30.7 \pm 5.9$ & $-2.88^{a}$ & .004 \\
\hline Gestational age at first prenatal visit, wk, mean \pm SD & $11.3 \pm 6.0$ & $15.2 \pm 7.3$ & $-4.50^{\mathrm{a}}$ & $<.001$ \\
\hline Gestational age at first prenatal scan, wk mean \pm SD & $14.3 \pm 7.6$ & $19.6 \pm 7.6$ & $-4.43^{a}$ & $<.001$ \\
\hline Level of maternal education, y median (range) & $11(0-8)$ & $8(1-8)$ & $24.56^{b}$ & $<.001$ \\
\hline Prenatal visits, $\mathrm{N}$, median (range) & $9(4-9)$ & $5(0-9)$ & $40.76^{b}$ & $<.001$ \\
\hline Prenatal ultrasound scans, N, median (range) & $4(2-7)$ & $3(0-6)$ & $12.28^{\mathrm{b}}$ & .001 \\
\hline Pregnancies, N, median (range) & $2(1-4)$ & $2(1-5)$ & $0.54^{b}$ & .462 \\
\hline
\end{tabular}

at test.

bMann-Whitney test.

Figure 1. Gestational age (weeks) at sonographic detection of anencephaly in public and nonpublic hospitals.

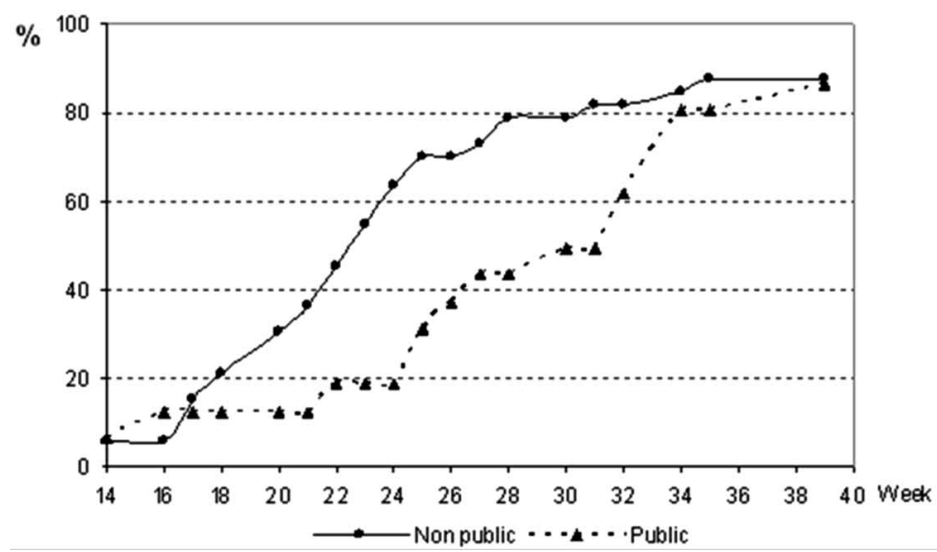

Figure 2. Gestational age (weeks) at sonographic detection of spina bifida in public and nonpublic hospitals.

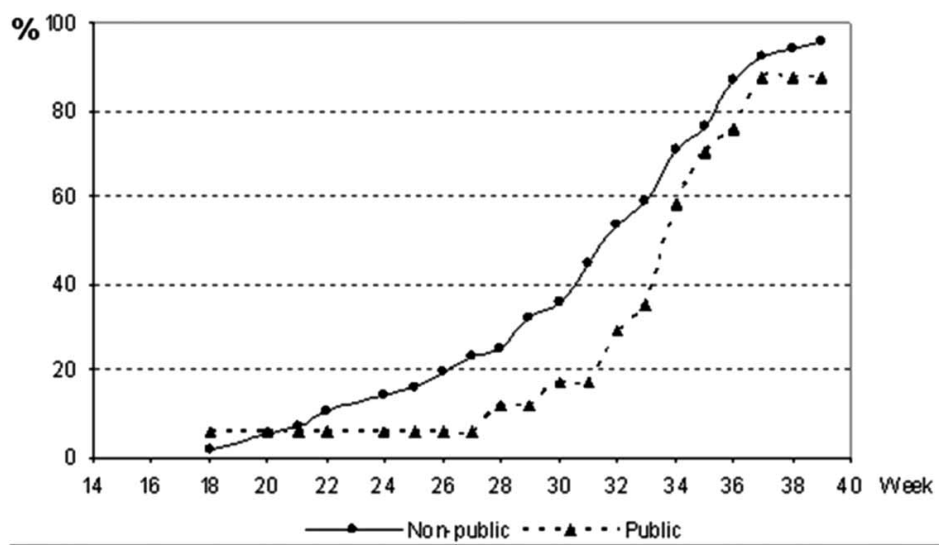

The global prenatal sonographic detection rate for the 450 cases followed until birth was $56.3 \%$. When comparing sensitivity rates among studies, some difficulties were found because of methodological differences such as criteria used for data collection and the exclusion of certain anomalies, usually not detected by routine sonographic studies, including heart defects and minor malformations. ${ }^{28}$ Thus, other studies have shown a wide range of detection rates for fetal malformations, from $13.3 \%$ in Ireland to $81.8 \%$ in the United Kingdom. ${ }^{2,3}$ Levi $^{3}$ showed $40.4 \%$ total sensitivity and average sensitivity of $55 \%$ and $92 \%$ for population samples at regular and high risk, respectively.

The method used to evaluate sonographic screening studies may vary considerably. Sensitivity is influenced considerably by several factors, such as the population selected, public health policies, gestational age at screening, total number of sonographic scans, distribution of malformations among different health insurance schemes, exclusion of fetal malformations, accuracy of neonatal examinations, training of practitioners in charge of the examinations, technological equipment used, and period of ascertainment. ${ }^{3,29,30}$

The distribution of malformations in this population probably differed from those observed in developed countries. The lack of health policies for the prenatal diagnosis of anomalies as well as pregnancy termination could have influenced the whole spectrum of anomalies and increased the number of fetuses with more than 1 anomaly. However, it might have affected the global but not the specific sensitivity for each given malformation. 
Detection rates reported by the Eurofetus Study, ${ }^{2}$ one of the largest screening studies published, were similar to those found in this study and varied according to the malformation. They were high for renourinary, abdominal wall, and central nervous system anomalies and low for cleft lip and heart malformations. The $89.7 \%$ detection rate observed in this study for renourinary anomalies was similar to that reported by Wiesel et $\mathrm{al}^{31}$ in about 700,000 births from 12 European countries, and the $58.5 \%$ detection rate for heart defects was comparable with the $57 \%$ rate reported in a recent study on 30,149 fetuses from an unselected population..$^{32,33}$

This study showed that detection rates also vary depending on the presence of other fetal malformations. The observation of several anomalies on sonography leads to an in-depth search for other anomalies, mainly those difficult to detect, such as heart and great vessel anomalies, cleft lip with or without cleft palate, clubfoot, and skeletal malformations. ${ }^{2}$

The average gestational age at diagnosis, varying according to the type of anomaly, was higher than that reported by other studies such as Eurofetus. ${ }^{2}$ Of all malformations observed, $75 \%$ were detected after 24 weeks, reflecting late diagnosis. When the sample was divided by the health insurance schemes of the mothers, patients from nonpublic hospitals had earlier gestational ages at detection than those from public hospitals, even though detection rates were similar for both health schemes. Furthermore, the average numbers of prenatal visits and sonographic examinations were significantly higher for patients from nonpublic hospitals than those from public hospitals. These differences could reflect the unequal access of mothers to prenatal care (first sonographic scan at a later gestational age for patients from public hospitals than those from nonpublic hospital and later admission of patients to public hospitals for prenatal control). Women from public hospitals were more often single, adolescent, and less educated and had poorer medical histories compared with those from nonpublic hospitals. ${ }^{34}$

Detection of birth defects affects pregnancy termination rates in most European countries. ${ }^{4}$ Grandjean et $\mathrm{al}^{2}$ reported voluntary termination in $27 \%$ of pregnancies with birth defect diagnoses and $41 \%$ when defects were severe; $83 \%$ of these terminations were performed before 24 weeks' gestation. However, this is not the case for South America, where pregnancy termination after any malformation diagnosis is not legal, except for anencephaly in some cities where the judge may grant a special permit under variable circumstances.

\section{Weaknesses}

Because of the relatively small sample size in our study, very rare anomalies were not included for detection rate evaluation. A bias in the classification of public and nonpublic hospitals cannot be disregarded. Although public hospitals assist patients without health insurance, nonpublic

Table 5. Sonographic Detection Rates and Gestational Ages at Diagnosis of Congenital Malformations for Nonpublic and Public Hospitals at Birth

\begin{tabular}{|c|c|c|c|c|c|c|c|c|}
\hline \multirow[b]{2}{*}{ Anomaly } & \multicolumn{4}{|c|}{ Nonpublic } & \multicolumn{4}{|c|}{ Public } \\
\hline & $\mathbf{N}$ & TP & DR, \% & GA, wk & $\mathbf{N}$ & TP & DR, \% & GA, wk \\
\hline Spina bifida & 50 & 48 & 96.0 & $30.7 \pm 5.2$ & 16 & 14 & 87.5 & $33.1 \pm 4.6^{a}$ \\
\hline Renourinary system & 64 & 57 & 89.1 & $28.8 \pm 6.4$ & 23 & 21 & 91.3 & $31.6 \pm 6.8^{a}$ \\
\hline Anencephaly & 33 & 29 & 87.9 & $22.8 \pm 5.0$ & 15 & 13 & 86.7 & $29.1 \pm 6.7^{a}$ \\
\hline Abdominal wall & 30 & 27 & 90.0 & $26.6 \pm 6.3$ & 8 & 6 & 75.0 & $26.8 \pm 5.8$ \\
\hline OSA of brain & 23 & 17 & 73.9 & $27.3 \pm 6.6$ & 13 & 11 & 84.6 & $28.9 \pm 6.4$ \\
\hline Hydrocephaly & 57 & 48 & 84.2 & $30.1 \pm 5.9$ & 21 & 15 & 71.4 & $31.5 \pm 6.4$ \\
\hline Heart and great vessels & 54 & 33 & 61.1 & $28.5 \pm 5.5$ & 11 & 5 & 45.5 & $30.3 \pm 6.5$ \\
\hline Skeletal & 45 & 25 & 55.6 & $27.7 \pm 5.2$ & 12 & 5 & 41.7 & $29.0 \pm 2.6$ \\
\hline $\mathrm{CL} / \mathrm{P}$ & 18 & 12 & 66.7 & $28.1 \pm 5.8$ & 8 & 4 & 50.0 & $33.5 \pm 1.3^{a}$ \\
\hline Limbs & 50 & 10 & 20.0 & $28.7 \pm 5.2$ & 17 & 3 & 17.6 & $31.8 \pm 6.0$ \\
\hline Clubfoot & 37 & 8 & 21.6 & $29.1 \pm 6.0$ & 10 & 1 & 10.0 & $28.5 \pm 12.0$ \\
\hline
\end{tabular}

$\mathrm{GA}$ indicates gestational age at diagnosis (mean $\pm \mathrm{SD}$ ). Other definitions are as in Table 1.

a $P<.05$, $t$ test. 
hospitals provide assistance to those with a mixed insurance scheme, either direct or indirect. The referral of patients from and to ECLAMC hospitals might have led to overestimates or underestimates in prenatal detection rates and could have represented a bias in our study.

\section{Strengths}

The sample was obtained from 18 South American hospitals, and 450 cases with prenatal diagnoses could be followed to birth. The characteristics of the hospitals included in this study are quite comparable with those of other hospitals in the region.

To our knowledge, a study evaluating prenatal detection of birth defects in South American populations has not been reported previously, and this study could provide a methodological basis for setting up a sonographic registry. The accuracy of prenatal sonographic detection of specific birth defects was assessed and validated with careful diagnostic precision. A committed professional team was in charge of every step of the study: prenatal diagnoses were made by the same sonographers, and neonatal examinations were performed by pediatricians highly trained in the diagnosis of birth defects who participate in the ECLAMC, a program with more than 40 years of experience in recording birth defects in South America. This study, and others that might follow, will allow assessment of the impact of sonography on the short- and long-term outcomes of malformed neonates in South America.

\section{Conclusions}

The detection rates reported here are similar to those found by other authors for populations at low risk. These rates varied according to the type of anomaly. Despite cultural and socioeconomic differences between South America and developed countries, similar performance of prenatal sonographic detection and diagnosis of birth defects was observed. The gestational age at detection was later for South American populations than reported for other countries. For some birth defects, an early gestational age at detection depends on the type of health insurance scheme.

\section{Members of the Study Group}

Participants and registries of The Latin American Collaborative Study of Congenital Malformations contributing to the study (numbers in parentheses are ECLAMC hospital codes): Argentina: Hospital Lucio Meléndez, Adrogué (303), Beatriz Minoli, MD; Hospital Ramón Sardá, Buenos Aires (318), Mónica Rittler, PhD; Hospital Francisco Santojanni, Buenos Aires (322), Carlos Persini, MD, Daniela Rottenberg, MD; Hospital Luisa C. de Gandulfo, Buenos Aires (325), Viviana Raquel Cosentino, PhD; Hospital Italiano de Buenos Aires, Buenos Aires (330), Horacio Aiello, MD; Hospital Narciso López, Buenos Aires (332), Mónica Adriana Jewtuszyk, MD; Hospital Privado de la Comunidad, Mar del Plata (406), Martín Roubicek, PhD; Maternidad Martín, Rosario (413), Margarita Nura Mussi, MD, Silvia Carbognani, MD, Susana Morales, MD; Hospital Italiano de La Plata (416), Mónica Ermini, MD, Alfredo Uranga, MD; Hospital Interzonal Dr J. Penna, Bahía Blanca (418), Carlos Deguer, MD; Hospital Regional A.

Perrupato, Mendoza (605), Carlos José Negri, MD; Hospital Enrique Vera Barrios, La Rioja (809), Susana Carrizo, MD; Hospital Zonal de Esquel (906), Rodolfo Lombardelli, MD.

Brazil: Maternidad Carmela Dutra, Florianópolis (A04), Aurea Gomez Nogueira, PhD, Eliana Ternes Perira, PhD; Hospital de Clínicas, Porto Alegre (A25), Julio César Loguercio Leite, $M D$; Hospital Centro de Atencíon Integral a la Salud de la Mujer, Campinas (A33), Denise Pontes Cavalcanti, PhD.

Chile: Hospital Clínico de la Universidad J. J. Aguirre (201), Santiago, Jorge Catalán Martínez, MD, Julio Nazer Herrera, PhD.

Venezuela: Maternidad Castillo Plaza, Maracaibo (F01), Rosa Cedeño, PhD. 
Appendix: Malformation Case Form

Identification case:

Patient number:

Sonologist:

Gestational age

Last menstrual period: weeks

First sonographic scan: weeks

Sonographic scan date: ______ day/month/year

Biparietal diameter: $\mathrm{mm}$

Femur length: $\mathrm{mm}$

Abdominal circumference: $\mathrm{mm}$

Estimated delivery date: day/month/year

Mark bodies and/or affected systems:

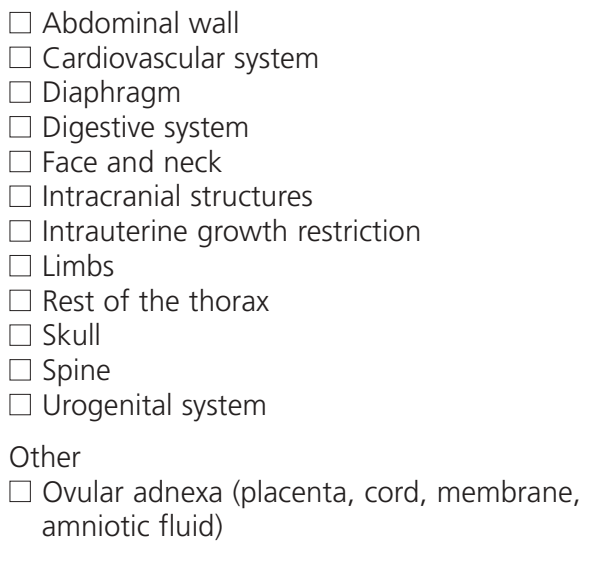

Description of the anomaly/anomalies:

Suspected diagnosis:

\section{References}

1. Clementi M, Stoll C. The Euroscan Study. Ultrasound Obstet Gynecol 2001; 18:297-300.

2. Grandjean $\mathrm{H}$, Larroque $\mathrm{D}$, Levi $\mathrm{S}$. The performance of routine ultrasonographic screening of pregnancies in the Eurofetus Study. Am J Obstet Gynecol 1999; 181:446454.

3. Levi S. Ultrasound in prenatal diagnosis: polemics around routine ultrasound screening for second trimester fetal malformations. Prenat Diagn 2002; 22:285-295.

4. Levi S, Montenegro NA. Eurofetus: an evaluation of routine ultrasound screening for the detection of fetal defectsaims and method. Ann NY Acad Sci 1998; 847:103-117.

5. Levi S, Schaaps JP, De Havay P, Coulton R, Defoort P. Endresult of routine ultrasound screening for congenital anomalies: the Belgian Multicentric Study 1984-92. Ultrasound Obstet Gynecol 1995; 5:366-371.

6. Garne E, Loane M, Dolk H, et al. Prenatal diagnosis of severe structural congenital malformations in Europe. Ultrasound Obstet Gynecol 2005; 25:6-11.

7. Magriples U, Copel JA. Accurate detection of anomalies by routine ultrasonography in an indigent clinic population. Am J Obstet Gynecol 1998; 179:978-981.

8. Waller DK, Pujazon MA, Canfield MA, Scheuerle AE, Byrne $\mathrm{JL}$. Frequency of prenatal diagnosis of birth defects in Houston, Galveston and the Lower Rio Grande Valley, Texas 1995. Fetal Diagn Ther 2000; 15:348-354.

9. Stefos T, Plachouras N, Sotiriadis A, et al. Routine obstetrical ultrasound at 18-22 weeks: our experience on 7,236 fetuses. J Matern Fetal Med 1999; 8:64-69.

10. Lee K, Kim SY, Choi SM, et al. Effectiveness of prenatal ultrasonography in detecting fetal anomalies and perinatal outcome of anomalous fetuses. Yonsei Med J 1998; 39: 372-382.

11. Boyd PA, Chamberlain P, Hicks NR. 6-year experience of prenatal diagnosis in an unselected population in Oxford, UK. Lancet 1998; 352:1577-1581.

12. Nakling J, Backe B. Routine ultrasound screening and detection of congenital anomalies outside a university setting. Acta Obstet Gynecol Scand 2005; 84:1042-1048.

13. Nikkilä A, Rydhstroem $H$, Källén B, Jörgensen C. Ultrasound screening for fetal anomalies in southern Sweden: a population-based study. Acta Obstet Gynecol Scand 2006; 85:688-693.

14. Belizán JM, Farnot U, Carroli G, al-Mazrou Y. Antenatal care in developing countries. Paediatr Perinat Epidemiol 1998; 12:1-3.

15. Penchaszadeh VB. Community genetics in Latin America: challenges and perspectives. Community Genet 2000; 3:124-127.

16. Gadow E, Petracchi F, Igarzabal L, Gadow A, Quadrelli R, Krupitzki H. Awareness and attitude toward prenatal diag- 
nosis of chromosomal abnormalities in patients with no access to legal termination of pregnancy. Prenat Diagn 2006; 26:885-891.

17. Christianson A, Modell B. Medical genetics in developing countries. Annu Rev Genomics Hum Genet 2004; 5:219265.

18. Leal Mdo C, da Gama SG, da Cunha CB. Racial, sociodemographic, and prenatal and childbirth care inequalities in Brazil, 1999-2001 [in Portuguese]. Rev Saude Publica 2005; 39:100-107.

19. Costa CM, da Gama SG, Leal Mdo C. Congenital malformations in Rio de Janeiro, Brazil: prevalence and associated factors. Cad Saude Publica 2006; 22:2423-2431.

20. Castilla EE, Orioli IM. ECLAMC: the Latin-American collaborative study of congenital malformations. Community Genet 2004; 7:76-94.

21. Penchaszadeh VB. Genetic services in Latin America. Community Genet 2004; 7:65-69.

22. Castillo-Taucher S. Genetic services in Chile. Community Genet 2004; 7:121-125.

23. Horovitz DD, Cardoso MH, Llerena JC Jr, de Mattos RA. Birth defects in Brazil and health care: proposals for public policies in clinical genetics. Cad Saude Publica 2006; 22:2599-2609.

24. Boyle CA, Cordero JF. Birth defects and disabilities: a public health issue for the 21st century. Am J Public Health 2005; 95:1884-1886.

25. Fuchs IB, Müller $H$, Abdul-Khaliq H, Harder T, Dudenhausen JW, Henrich W. Immediate and long-term outcomes in children with prenatal diagnosis of selected isolated congenital heart defects. Ultrasound Obstet Gynecol 2007; 29:38-43.

26. Jaeggi ET, Sholler GF, Jones OD, Cooper SG. Comparative analysis of pattern, management and outcome of pre- versus postnatally diagnosed major congenital heart disease: a population-based study. Ultrasound Obstet Gynecol 2001; 17:380-385.

27. Toy EC, Montealegre Al, Fernandez LP, Harms KP, Kaplan AL. Is fetal anatomic assessment on follow-up antepartum sonograms clinically useful? J Ultrasound Med 2007; 26:1175-1179.

28. Sabbagha RE, Sheikh Z, Tamura RK, et al. Predictive value, sensitivity, and specificity of ultrasonic targeted imaging for fetal anomalies in gravid women at high risk for birth defects. Am J Obstet Gynecol 1985; 152:822-827.

29. Papp Z, Fekete T. The evolving role of ultrasound in obstetrics/gynecology practice. Int J Gynaecol Obstet 2003; 82: 339-346.

30. Seeds JW. The routine or screening obstetrical ultrasound examination. Clin Obstet Gynecol 1996; 39:814-830.

31. Wiesel A, Queisser-Luft A, Clementi M, Bianca S, Stoll C; Euroscan Study Group. Prenatal detection of congenital renal malformations by fetal ultrasonographic examination: an analysis of 709,030 births in 12 European countries. Eur J Med Genet 2005; 48:131-144.
32. Tegnander E, Williams W, Johansen OJ, Blaas HG, Eik-Nes $\mathrm{SH}$. Prenatal detection of heart defects in a non-selected population of 30,149 fetuses: detection rates and outcome. Ultrasound Obstet Gynecol 2006; 27:252-265.

33. Todros T, Faggiano F, Chiappa E, Gaglioti P, Mitola B, Sciarrone A. Accuracy of routine ultrasonography in screening heart disease prenatally. Gruppo Piemontese for Prenatal Screening of Congenital Heart Disease. Prenat Diagn 1997; 17:901-906.

34. Belizán JM, Althabe F, Barros FC, Alexander S. Rates and implications of caesarean sections in Latin America: ecological study. BMJ 1999; 319:1397-1400. 